\title{
Definición, apropiación y construcción del espacio en la tierra austral incógnita ${ }^{1}$
}

\author{
Carolina Martínez \\ Facultad de Filosofía y Letras, UBA / CONICET
}

\section{Resumen}

La Tierra Austral Incógnita en tanto espacio geográfico pero también tópico en la literatura de viaje europea de la primera modernidad jugó un papel de singular importancia en la Francia de mediados del siglo XVII, al cumplir con la doble función de justificar la expansión ultramarina y a su vez convertirse en depositaria de las múltiples sociedades imaginarias que en esta época se concibieron.

Ciertamente, fueron las primeras exploraciones al Pacífico Sur las que en gran medida alimentaron el mito de la tierra austral. Pero es al redescubrimiento y reinterpretación de los textos antiguos que tuvo lugar en Europa a partir del siglo XV que también debe atribuirse el hecho de que nociones premodernas se convirtieran ahora en las fuerzas propulsoras de aquella expansión a los confines del mundo. En el caso particular de la literatura utópica francesa de mediados del siglo XVII, representación y experiencia harán de la tierra austral incógnita el espacio de la alteridad más absoluta. El hecho de que en 1771 diera Cook pruebas irrefutables de la inexistencia de aquella gran masa continental, no deberá por ello hacer que su valor en tanto representación de un espacio deseable en el horizonte de la expansión ultramarina así como también campo propicio para la reflexión filosófica en la Francia moderna sea desestimado. Palabras clave: Tierra Austral Incógnita - expansión ultramarina - viajes imaginarios

\begin{abstract}
The Terra Australis Incognita both as a geographical space and a topic in travel literature in the Early Modern Age played a relevant role in mid-17th century France, as it fulfilled the double task of justifying overseas expansion and stage-setting the many imaginary societies envisaged during this period.

Certainly, it was the first navigation to the South Pacific that intensified the myth of an Austral land. However, it is to the rediscovery and reinterpretation of the Ancient texts that took place in Europe as from the 15 th century that we should also attribute the fact that pre-modern notions now turned into the driving force of overseas expansion. In the particular case of mid-17th French utopian literature,
\end{abstract}

1 Una versión preliminar de este artículo fue presentada en el I Taller de Jóvenes Investigadores de las Jornadas de la División de Historia de la Universidad de Luján en el mes de agosto de 2011. Las notas y citas de este artículo procuran transcribir completos los títulos de los libros citados, en su ortografía original .

MARTÍNEZ, Carolina, “ Definición, apropiación y construcción del espacio en la Tierra Austral Incógnita” en Avances del Cesor, Año VIII, N 8, 2011, pp. 91-110. 
representation and experience will make the Austral land-unknown home of the most radical otherness. The fact that in 1771 Cook proved the inexistence of this large continental mass, should therefore not, by any means, make us dismiss the importance of the terra australis incognita as a motivating force behind France's ambitions overseas nor its stimulating effects in Modern philosophical thought.

Key words: Terra Australis Incognita - overseas expansion - imaginary voyages

En un ya clásico estudio sobre el mal llamado descubrimiento de América, Edmundo O’Gorman sostenía que debía considerarse la aparición histórica de América como “... el resultado de una invención del pensamiento occidental y no ya como el de un descubrimiento meramente físico, realizado, además, por casualidad." ${ }^{2}$ Suponía ésto entender a la historia como un proceso productor de entidades históricas y, por ello, a la invención de América como nacida a partir de una imagen del mundo determinada. ${ }^{3}$

Ahora bien, en la influencia recíproca entre representación y experiencia, existe a su vez la posibilidad de que dichas entidades históricas también escapen y tomen una densidad propia en un período de larga duración y a través del mundo social. ${ }^{4}$ En efecto, el estudio de la Tierra Austral en tanto ente histórico, producto de una determinada imagen y concepción del mundo, bien podría demostrar que si bien sus orígenes pueden retrotraerse a la antigüedad más clásica, la dinámica y novedades de la temprana modernidad europea le otorgaron una nueva dimensión histórica, al convertirse desde el siglo XVI no solamente en el horizonte deseado de la expansión ultramarina sino también en depositario de fantasías utópicas. Es desde esta perspectiva entonces que a continuación se analizarán, partiendo desde sus remotos orígenes hasta entrado el siglo XVIII, los usos y el lugar ocupado por la tierra austral incógnita en el imaginario europeo de la modernidad clásica.

\section{La Tierra Austral Incógnita: definición y particularidades}

Explicar los orígenes de un concepto tal como el de la tierra austral incógnita requiere en gran medida indagar acerca de las concepciones cosmográficas sostenidas desde la Antigüedad en torno a una específica serie de temas intrínsecamente relacionados. En este sentido, la hipotética existencia de una gran masa continental en el extremo sur del mundo debería ser comprendida en el más amplio grupo de indagaciones acerca de la circunferencia del globo, su esfericidad, o qué porciones del mismo estaban cubiertas por mar o tierra.

2 O’GORMAN, Edmundo, La invención de América, Fondo de Cultura Económica, México, (1958) 2006, p. 9.

3 Ibídem, p. 12.

4 CHARTIER, Roger, El mundo como representación. Historia cultural: entre práctica y representación, Gedisa, Barcelona, 1996, p. 11. 
Aspectos que se convirtieron entre otras incógnitas, no solamente en desafíos frente a los cuales los Antiguos brindaron sus propias respuestas sino en cuestiones que continuarían siendo debatidas hasta entrado el siglo XV. ${ }^{5}$

En efecto, la teoría de las antípodas, que defendía la existencia de una porción de tierra diametralmente opuesta al orbis terrarum y que actuaba como su contrapeso, ${ }^{6}$ carecería de sentido si no se tomase en cuenta que a partir de la tesis aristotélica y, con algunas variaciones, hasta fines del siglo XV, se creyó en el carácter insular de la tierra, y por ello, en el hecho de que estuviera rodeada por agua. En este sentido, resulta interesante señalar que la idea de un mundo dividido en dos zonas climáticas simétricas a partir de un eje equinoccial es todavía anterior, dado que la noción de las antípodas había sido introducida por Parménides en época tan temprana como el siglo $\mathrm{V}$ a. C. ${ }^{7}$

Ahora bien, que se creyera en la insularidad de la tierra llevó, con más o menos vigor según la época, a que surgiera la inevitable pregunta respecto de la existencia de otras islas comparables en otros hemisferios. Como bien ha señalado O'Gorman sobre este punto, “... para los griegos, si la Isla de la tierra era pequeña, había más posibilidades de que existieran tierras antípodas habitadas." 8

En siglos posteriores, sin embargo, esta idea será descartada, al encontrarla la Iglesia inaceptable por el hecho de oponerse a la procedencia única del género humano producto de una sola y original pareja. Que la Iglesia la descartara, no obstante, no significó que en ciertos ámbitos esta teoría no siguiera cosechando adeptos. Los irreverentes escritos de Gabriel Foigny, un antiguo capuchino devenido pastor pero igualmente marginal en 1676, resultan una clara prueba de aquello. En el mismo sentido, las adhesiones a la teoría preadamítica sostenida por Isaac de La Peyrère o las heterodoxas interpretaciones de Mademoiselle Bourignon para esta misma época, también serán prueba de ello.

Resultaba claro, sin embargo, que la interpretación canónica negaba la existencia de las tierras antípodas, y con ella, el hecho de que estuvieran habitadas. Sobre este último punto debe señalarse incluso que en el caso de quienes como San Isidoro de Sevilla admitían la existencia de una cuarta parte del mundo, no consentían en el hecho de que ésta estuviera habitada.

5 En relación a esta temática, uno de los estudios más completos en torno a los vínculos entre una y otra teoría así como a su desarrollo en siglos posteriores ha sido Le continent austral: hypothèses et découvertes (1893) de Armand Rainaud. Dividiendo su obra en tres grandes apartados en función de los orígenes y ocaso del concepto. Ver RAINAUD, Armand, Le continent austral: hypothèses et découvertes, Armand Colin, Paris, 1893.

6 O'GORMAN, Edmundo, La invención..., Op. Cit., p. 169.

7 FAUSETT, David, Writing the New World. Imaginary voyages and utopias of the Great Southern Land, Syracuse University Press, New York, 1993, p. 10.

8 O'GORMAN, Edmundo, La invención..., Op. Cit., p. 62. 
Basculando entre las suposiciones más antiguas y los recortes impuestos por la Iglesia en un período posterior, la curiosidad frente a la posible existencia y poblamiento de tierras australes sobreviviría no obstante a las distintas épocas. Fueron dos sucesos de cabal importancia para la geografía moderna, sin embargo, los que crearon aún más expectativas en torno al mencionado dilema: el hallazgo del Comentario de Macrobio y del mapa diseñado en el siglo X a partir de sus escritos por un lado, y la traducción al latín de la Geographia de Ptolomeo a principios del siglo XV por el otro.

Cerca del siglo V d.C. en su Comentario al Somnium Scipionis de Cicerón, Aurelio Teodosio Macrobio había sostenido la idea de un mundo compuesto por cuatro porciones de tierra, las cuales eran habitables y podían incluso estarlo por otro género de hombres. Las conclusiones de Macrobio, sin embargo, habían trascendido su propia época y en el siglo $\mathrm{X}$ se habría dibujado un mapa en el que se ilustraban estas ideas. Impreso por primera vez en Brescia, en 1483, las mismas devinieron nuevamente protagonistas al reactivar una vez más el debate en torno a la posible existencia de moradores desconocidos en las antípodas de la tierra.

Por su parte, la Geographia de Ptolomeo parece haber causado un impacto todavía mayor en la forma de abordar las representaciones cartográficas de aquél mismo período. Tal como fue traducida en el siglo XV, ha sostenido Crombie, la Geographia parecía ser al menos parcialmente, una compilación tardía y así como con Macrobio, existe la posibilidad de suponer que los mapas incluidos en esta reedición del texto clásico fueron en realidad hechos por artistas bizantinos de los siglos XIII y XIV. Fue la obra de Ptolomeo la que ofreció por vez primera al lector de la temprana modernidad mapas con sus respectivos paralelos y meridianos. Recobrada y traducida al latín por Giacomo d'Angelo en 1406, objeto de numerosas ediciones y posteriores traducciones, los mapas en ella exquisitamente redibujados muy pronto acompañarían a navegantes y aventureros en sus viajes interoceánicos. ${ }^{10}$

En efecto, a partir de 1477, “... fecha en la que se publicó la Geographia en Bolonia, por vez primera con los mapas de Ptolomeo", ${ }^{11}$ con la difusión de las múltiples ediciones de este manuscrito y sobre todo del atlas del mundo que éstas incluían, la Tierra Austral en

9 CROMBIE, Alistair Cameron, Historia de la Ciencia, Alianza Universidad, Madrid, (1974) 2006, T. I, p. 190.

10 ZUMTHOR, Paul, La medida del mundo. Representación del espacio en la Edad Media, Cátedra, Barcelona, 1994, p. 320: "La Geographia era en realidad un tratado de cartografía más que una descripción del mundo; los mapas que la ilustraban eran sin duda muy posteriores al texto, pero la obra se consideró como un todo. Traducida al latín antes de 1409, se extendió inmediatamente entre los medios intelectuales de Italia, de Francia, de Alemania. En 1475 se imprimió sólo el texto; en 1477, el texto y los mapas. Siguieron varias reediciones. Esta oleada fue contemporánea de las grandes expediciones." Ver también PARRY, John, El descubrimiento del mar, Crítica, Barcelona, 1989, p. 89.

11 CROMBIE, Alistair Cameron, Historia ..., Op. Cit., T. I, p. 191.

\section{4}


tanto espacio real y ubicable a partir de una serie de coordenadas comenzó a ocupar un lugar por demás relevante en el imaginario del hombre moderno. Fue la versión de Ptolomeo que se conoció en Europa en el siglo XV, ha señalado Parry, la que nuevamente presentaría a “... una vasta masa de tierra continental [extendiéndose] a través del sur del océano Índico desde África hasta el extremo más lejano de Asia."12

De tal forma, en las décadas subsiguientes, ningún mapa que se preciara de ser exacto dejaría de respetar la tradición ptolemaica y así de incluir al orbis alterius como una gran masa de tierra en los confines septentrionales del globo. En este sentido resulta interesante señalar que el mismo Waldseemuller incorporaría en su atlas de 1507 los más recientes descubrimientos, incluida la nueva América, sin rezagar los componentes heredados de Geographia para ello. ${ }^{13}$

Es así como en su aventura hacia nuevos horizontes, el hombre europeo llevará consigo un mundo de representaciones que le permitirán articular lo desconocido en función de aquello que conoce. En términos de Zumthor, “... básicamente, los mismos principios cosmográficos, los mismos prejuicios simbólicos (con fuertes connotaciones teológicas) formaron, incluso hasta las primeras travesías del Atlántico, el entramado que tuvieron más o menos que utilizar para interpretar lo ajeno, es decir, diferenciarlo y dar cuenta de ello; concebirlo." ${ }^{14}$ Como veremos a continuación, fue éste un aspecto de crucial importancia al momento de abordar el impacto que las nuevas tierras descubiertas ejercerían en aquellas mismas representaciones.

A los principios geográficos heredados de la antigüedad y resignificados en función del presente, sin embargo, también deberíamos agregar aquellas vagas nociones sobre tierras lejanas que, desde el siglo XIII, proveyeron relatos de viaje como aquellos de Marco Polo, y que en el caso de este último, continúan siendo considerados por los estudiosos del caso la crónica más informativa y completa de Asia escrita por viajeros europeos en la Edad Media. ${ }^{15}$ Tampoco deberíamos olvidar Los viajes de Sir John Mandeville, que aunque ficticios,

12 PARRY, John, El descubrimiento del mar..., Op. Cit., p. 91.

13 ZUMTHOR, Paul, La medida ..., Op. Cit., p. 323: “... Martin Waldsemuller publica en SaintDié, a petición del duque de Lorena, una Cosmographiae introduction, mapa del mundo en el que se dibujan las costas del nuevo continente (detrás sólo se sugiere una estrecha franja de tierra): dos partes diferentes, llevando la más meridional el texto América. Mercator adoptará definitivamente esta denominación en 1538. Sin embargo, es con los Verrazano, en 1527 y después en 1529, cuando toma forma la tradición nueva de los mapas de América."

14 Ibídem, p. 248.

15 PARRY, John, El descubrimiento del mar..., Op. Cit. p. 79-80: "Su posición privilegiada de funcionario imperial y los viajes que hizo en esa calidad le brindaron oportunidades excepcionales para recoger información.... sus descripciones de la administración del imperio, de ciudades, canales, ríos, puertos, industrias y recursos naturales son vívidas y convincentes. ... Donde más en boga estuvo el libro fue en Italia, Francia y los Países Bajos.” Ver también FAUSETT, David, Writing..., Op. Cit., p. 11. 
representaron un giro en la evolución del pensamiento geográfico europeo al describir “.... casi todas las partes del mundo sobre las que se disponía de testimonios literarios." ${ }^{\prime 6}$ Más allá de estos pilares de referencia debe, sin embargo, decirse que en relación a la Tierra Austral específicamente la verdadera explosión de datos que se creyeron certeros acerca de esta zona se daría una vez iniciada la expansión ultramarina. En este sentido, fueron los avances técnicos de la época los que permitieron al hombre acortar distancias entre lo conocido y aquello que restaba por conocer; ${ }^{17} \mathrm{y}$ en este proceso, llevar a sus límites la domesticación del espacio. Como ha señalado Paul Zumhtor:

...la mayor parte de los sucesores de Colón, a partir de 1500, serán hombres de ciencia tanto como aventureros. El desafío de sus expediciones no es solamente un conocimiento de la Tierra, sino una confirmación del control humano sobre la Creación... ${ }^{18}$

\section{La apropiación de un espacio desde la literatura utópica}

Entre los siglos XVI y XVIII fueron considerables los esfuerzos realizados en pos de delinear con aún más precisión el lugar ocupado por las tierras australes supuestas por los Antiguos. Aunque como hemos dicho, la experiencia real del viaje y aquello que se apuntaba haber observado respondiera en gran parte al imaginario popular, tan presente en la mente de exploradores y aventureros, sobre qué podía esperarse hallar.

En este proceso, los motivos edénicos o la creencia en una renovada Edad de Oro serán ahora depositados en un área geográfica determinada en y por el imaginario Europeo, pero aún por delimitar en términos geográficos. Así, las posibilidades ofrecidas por la desconocida Tierra Austral serán muchas y desde los distintos ámbitos, el literario, el político y el económico, devendrá éste el lugar de las grandes expectativas. En el caso de Francia particularmente, representarán estas tierras el imperio colonial por construir, las posibles riquezas a obtener y el no-lugar donde se construyan sociedades ideales. Como ha señalado Paul Zumthor, en términos generales, no existe duda alguna de que es bajo el signo del imaginario que, desde el siglo XV, se desarrollará el descubrimiento del mundo. En consonancia con ello, “... la extensión que se abre, el espacio que se conquista, es también la otra cara de la realidad, antimundo donde se proyectan libremente nuestras fantasías."19

16 PARRY, John, El descubrimiento del mar..., Op. Cit., pp. 82-83.

17 PARRY, John, Europa y la expansión del mundo (1415-1715), Fondo de Cultura Económica, México, 1952, p. 15: "La pericia técnica y la capacidad para aplicar el conocimiento teórico a fines materiales prácticos, han sido factores principales en la extensión de la influencia europea por todo el mundo...".

18 ZUMTHOR, Paul, La medida ..., Op. Cit., p. 243.

19 Ibídem, p. 240-241.

96 
Al momento de trazar mapas, tampoco serán representadas estas tierras como lugares vacíos:

El cartógrafo concentra en estos espacios inciertos lo que les sugiere su fantasía o su ciencia: imágenes monstruosas, inscripciones (“Aquí sólo existen tierras áridas...”) o el simple reticulado de los rumbos, y la representación de los vientos. El vacío, en efecto, es absurdo, ni más ni menos. ${ }^{20}$

Vemos entonces como en una intrincada combinación de supuestos teóricos y realidades materiales no del todo comprobables, hacia mediados del siglo XVII la especulación sobre la existencia de tierras australes era alimentada desde diferentes flancos. Para la literatura utópica en el caso de Francia particularmente, los escritos propagandísticos de Pedro Fernández de Quirós (destinados al rey de España pero traducidos a otras lenguas en esta misma época), la actividad comercial holandesa en las Indias Orientales, y el nada preciso pero igualmente efectista relato de viaje de Binot Paulmier de Gonneville a tierras australes devendrán una fuente de inspiración inagotable y en total disponibilidad para quienes deseasen acceder a ella. ${ }^{21}$

A los intereses del presente trabajo, el caso de Pedro Fernández de Quirós resulta de particular importancia ya que al momento de escribir Gabriel Foigny en 1676 la Terre Australe Connue, será del Octavo Memorial de Quirós (1610) de donde más información obtenga para hacer de su fantasía utópica un texto verosímil. De tal forma, desde el prefacio, Foigny autenticará su relato de viaje vinculándolo a los viajes exploratorios iniciados por el navegante portugués, quien al servicio del Rey de España había navegado por el Pacífico Sur con la esperanza de descubrir la tan codiciada Tierra Austral, convertirla en posesión española y dar así nuevos bríos al ya alicaído imperio.

Enviado al Rey de España en 1610, el Octavo Memorial de Quirós era en realidad un desesperado pedido de apoyo a la corona que bajo el título completo de Copie de la Requeste présentée au Roy d'Espagne par le capitaine P. Ferdinand de Quir sur la découverte de la cinquiesme partie du Monde intitulée terre Australe incogneue22 (1617) sería en pocos años traducido y publicado al francés.

Siguiendo el modelo iniciado por Moro en 1516, desde los primeros párrafos Foigny citará los descubrimientos de Magallanes ${ }^{23}$ y del mencionado capitán Gonneville, entre otros,

20 Ibídem, p. 329.

21 FAUSETT, David, Writing..., Op. Cit., p. 22.

22 Copia del Requerimiento presentado al Rey de España por el Capitán P. Fernando de Quirós acerca del descubrimiento de la quinta parte del mundo llamada tierra Austral desconocida.

23 El primer viaje de circunnavegación comenzado por Magallanes y terminado por Juan Sebastián Elcano, descripto por Antonio Pigafetta en 1536, había despertado aún más la curiosidad sobre la existencia de un continente austral por el hecho de haber cruzado hacia el Océano Pacífico bordeando el extremo norte de Tierra del Fuego y haber desconocido justamente que se trataba de una isla. Ver 
argumentando la falta de datos precisos hasta el presente acerca de la Tierra Austral y sus habitantes. Seguidamente, sin embargo, destacará los esfuerzos de Fernández de Quirós y de su almirante Luis Paéz Torres ${ }^{24}$ quienes, dirá Foigny, a pesar de su magros resultados, al menos recabaron más datos que el resto sobre las desconocidas tierras australes:

Este es el resumen de los relatos de aquellos dos personajes cuya memoria no puede ser más que gloriosa; a continuación se verá que si bien ellos no recorrieron aquél vasto país, se acercaron mucho a él. No es este, sin embargo, más que un leve esbozo que altera más que satisface, puesto que no particulariza en nada. ${ }^{25}$

Foigny continuará validando su propia obra al remitirse a detalles y fragmentos escritos por Quirós en el Octavo Memorial a su Majestad Católica. Las informaciones presentadas al lector como el vivo testimonio del capitán y su almirante, sin embargo, no serán siempre del todo fidedignas y por momentos se asemejarán más a sus propias "descripciones" de los habitantes de la Tierra Austral que a las aparecidas en el memorial del navegante portugués. ${ }^{26}$ En términos generales, no obstante, en su Octavo Requerimiento, Quirós ya había retratado a la Tierra Austral como una tierra excelente por su clima, fertilidad, materias primas y extensión:

Diría que, como se verá a continuación, las tierras que he visto en el grado 15 son mejores que España, y que otras, que se encontraban en las alturas del frente, deberían ser un paraíso en la tierra. ${ }^{27}$

RAINAUD, Armand, Le continent austral..., Op. Cit., p. 3.

24 FOIGNY, Gabriel, La Terre Australe Connue, c'est-a-dire la description de ce pays inconnu jusqu'ici, de ses moeurs et de ses coûtumes para M. Sadeur, avec les avantures qui le conduisirent en ce Continent et les particularitez du séjour qu'il y fit durant trente-cinq ans et plus, et de son retour, réduites et mises en lumière par les soins et la conduite de G. F. À Vannes, par Jaques Verneuil, 1676, LACHĖVRE, Frédéric, Les successeurs de Cyrano de Bergerac, Librairie Ancienne Honoré Champion, Paris, 1922, p. 64: "Il est vrai que comparant la relation de Fernandes de Quir, Portugais, avec la description qui doit suivre, on est obligé d'avouer que si quelqu'un en est approché cet honneur lui est due privativement à tous ses devanciers". (Es cierto que comparando la relación de Fernández de Quirós, portugués, con la descripción que sigue, está uno obligado a admitir que si alguien se acercó, ese honor les es exclusivamente suyo y privativo a sus predecesores.)

25 FOIGNY, Gabriel, "La Terre Australe Connue,...", LACHĖVRE, Frédéric, La Terre Australe ..., Op. Cit., p. 65: "Voilà le racourci des rapports de ces deux personnages dont la mémoire ne peut estre que glorieuse, et la suite fera voir que, s'ils n'ont pas parcouru ces vastes pays, ils en ont approché de fort près. Ce n'est cependant qu'un léger crayon qui altère plus qu'il ne satisfait, puis qu'ils ne particularisent rien."

26 Mientras que Quirós describe a los hombres como de baja estatura y saludables, Foigny, al "reproducir" la descripción de Quirós los hace más grandes y altos.

27 The voyages of Pedro Fernández de Quirós, 1595 to 1606, Translated and Edited by Sir Clements 
Siendo que era ya la octava vez que Quirós pedía su apoyo al rey y que éste hacía caso omiso de dicho pedido, ${ }^{28}$ es posible pensar que fue el mismo Quirós quien ante tales circunstancias se vio compelido a describir hiperbólicamente las tierras australes por descubrir. ${ }^{29}$ De la misma manera, cabe suponer que el enigma construido en torno al carácter de los habitantes en el interior del continente también habría sido creado por el portugués, ansioso por entusiasmar al rey respecto de los beneficios que podría hallar España en aquellas tierras si éstas eran descubiertas. ${ }^{30}$

Como Quirós, quien había hecho particular hincapié en la abundante y sabrosa fruta hallada en tierras australes, Foigny hará de los australianos de la Terre Connue un pueblo frutívoro. ${ }^{31}$ Es también Quirós quien primero señala que las cálidas temperaturas y el clima

Markham, Hackluyt Society, London, 1904, Vol. II, Eighth Memorial submitted to His Majesty by the Captain Pedro FERNÁNDEZ de QUIRÓS on the subject of his discoveries, p. 478: "I would remark that the lands I saw in $15^{\circ}$ are better than Spain, as will be seen presently, and that others, which were on the heights in front, should be an earthly paradise."

28 Ibídem, p. 477: “...say that with this I have presented to Your Majesty eight memorials relative to the settlement which ought to be made in the land which Your Majesty ordered to be discovered in Austrialia Incognita; without, up to this time, any resolution being taken nor any reply made to me, nor hope given to assure me that I shall be sent out.” (... con ésto, he presentado a Vuestra Majestad ocho memoriales concerniendo el establecimiento que debería realizarse en las tierras que Vuestra Majestad ordenó fuesen descubiertas en la Austrialia Incognita; sin, hasta el momento, haber tomado ninguna resolución o haberme respondido, o haberme dado la esperanza de que allí seré enviado.)

29 Ibídem, p. 478: "The greatness of the land newly discovered, judging from what I saw, and from what the Captain Don Luis Paez de Torres, the Admiral under my command, reported to Your Majesty is well established." (La grandeza de la tierra recientemente descubierta, al juzgar por lo que he visto, y por lo que el Capitán Don Luis Paéz Torres, Almirante bajo mi mando, informó a Vuestra Majestad está bien establecida.)

30 Puede apreciarse lo dicho en frases como "On the whole, these are certain indications of the neighbourhood of a more civilized people, and it is no less an indication of this that they castrate their pigs and fowls" (En general, estas son algunas indicaciones de la proximidad de un pueblo más civilizado, y no es menor indicación de ello que castran a sus cerdos y aves.) (The voyages of Fernández de Quirós, Op. Cit., p. 480) o "I declare that all that was seen and has been described is on the sea shore; so that it may be hoped that in the heart of the country such a and so great riches will be found as are foreshadowed by what has already been seen." (Declaro que todo lo visto y descrito se encuentra en la costa, por lo que podría esperarse que en el centro del país tales y mayores riquezas puedan ser encontradas de la forma en que puede adelantarse por lo que ya ha sido visto.) (The voyages of Pedro Fernández de Quirós..., Op. Cit., p. 482)

31 FOIGNY, Gabriel, "La Terre Australe Connue,...”, en LACHÈVRE, Frédéric, La Terre Australe ..., Op. Cit., p. 92: “Ils n’ont ni four, ni marmite pour cuire acucune viande, ils ne sçavent ce que c'est que cuisine et cuisinier." (No tienen ni horno, ni marmita para cocinar carne alguna, no saben lo que es la cocina ni el acto de cocinar.) 
saludable habían impedido que sus navegantes enfermaran durante su estadía en aquellas regiones; ${ }^{32}$ algo que Foigny recalcará a través de Jacques Sadeur, su protagonista. Respecto del clima, nuevamente será Quirós quien primero celebre la ausencia de insectos y alimañas en el supuesto continente austral; ${ }^{33}$ aspecto que no dejará de señalar Foigny cada vez que se refiera a las maravillas de esta región:

No se ven ni moscas, ni orugas, ni ningún insecto, no saben lo que es una araña, ni una serpiente ni otras bestias venenosas. En una palabra, es un país bendecido que, conteniendo todas las rarezas y delicadezas imaginables, está exento de todas las incomodidades que nos rodean..$^{34}$

El impacto de los escritos de Quirós en la construcción de un espacio austral abundante en recursos y propicio para el asentamiento humano, así como a nivel literario también atractivo por el halo de misterio en torno a él creado, no debe pues ser desestimado. En términos geográficos, sus descubrimientos tampoco fueron menores. En el año de 1595 el portugués ya había acompañado a Álvaro de Medaña en sus incursiones por el Pacífico Sur y hacia esta misma época, también intentado colonizar las Islas Salomón. Su descubrimiento en 1606 de la Isla de Espíritu Santo, a la que en honor a la dinastía reinante llamó Austrialia del Espíritu Santo ha hecho de él, para muchos, el verdadero descubridor de Australia. Fueron sus escritos, sin embargo, los que más atrajeron la atención del público lector. En efecto, el gran compliador de viajes y grabador Theodoro De Bry no dudará en incluir hacia 1613 la versión latina del Octavo Memorial en su colección de Petit voyages.

En relación al viaje realizado por Binot Paulmier de Gonneville entre 1503 y 1505, y a la relación escrita a partir del mismo, es Michel Mollat quien más ha indagado al respecto e insertando a Gonneville dentro de la primera oleada de exploradores que intentaron sortear

32 The voyages of Pedro Fernández de Quirós..., Op. Cit., p. 484: “... the temperature and salubrity of the air is seen in all that has been said, and in this, that we all being strangers, none fell ill during a time of working..." (la temperatura y salubridad del aire se ve en todo lo antedicho, y en lo siguiente, que siendo todos extranjeros, ninguno cayó enfermo durante los tiempos de trabajo...)

33 Ibídem, p. 485: "I have not seen sand deserts, nor any kind of thistles, nor thorny trees, nor trees with roots above ground, nor mangroves, ... nor crocodiles in the rivers, nor poisonous reptiles in the woods, nor the ants that are very harmful in houses, nor jiggers, nor mosquitos." (No he visto desiertos, ni ningún tipo de cardo, ni árboles espinosos, ni árboles con raíces sobre el suelo, ni manglares, ... ni cocodrilos en el río, ni reptiles venenosos en los bosques, ni de las hormigas que son tan dañinas en las casas, ni pulgas, ni mosquitos.)

34 FOIGNY, Gabriel, La Terre Australe Connue,..., LACHĖVRE, Frédéric, La Terre Australe ..., Op. Cit., p. 94 : “On n'y voit ny mouches, ny chenilles, ny aucun insecte, ils ne savent ce que c'est qu'araignée, que serpens et qu'autres bêtes venimeuses. En un mot c'est un païs de bénédiction qui, contenant toutes les raretez et toutes les délicatesses imaginables, est exempt de toutes les incommoditez qui nous environnent." 
el obstáculo que representaba América en el camino occidental hacia Oriente, estudiando para ello el malogrado viaje de l'Espoir desde Honfleur. ${ }^{35} \mathrm{Al}$ respecto, debe señalarse que si bien en el siglo XVII se creyó que Gonneville también había navegado por tierras australes (es por esto que Foigny habría de incluirlo junto a Magallanes y Quirós en el prefacio al lector de la Terre Australe Connue), se corroboraría luego que en realidad sus exploraciones lo habían llevado a recorrer las costas de Brasil y no más al sur de éstas. La confusión originada a partir del relato de Gonneville y de las tierras por él visitadas, lejos de leerse como una mera equivocación, sin embargo, resulta bastante ilustrativa de los ambiguos límites que, aún entrado el siglo XVII, existían en torno a las que podían considerarse tierras australes o no. ${ }^{36}$

En este sentido, las incursiones holandesas en el Pacífico Sur en busca de nuevas rutas comerciales y especias también contribuyeron a enriquecer el imaginario espacio cartográfico atribuido a las Terrae Incognita. Retrasada respecto de España y Portugual, Holanda se precipitó a los mares del sur en un intento por dominar aquella región todavía inexplorada. De sus éxitos, pero por sobre todo de sus fracasos, nacerán varios mitos en torno a la Tierra Austral. En este sentido, más allá de que los orígenes del predominio holandés en el área puedan datarse hacia 1596, dichas incursiones no impedirán que se siga especulando en torno a la existencia de esta región hasta bien entrado el siglo XVIII:

En 1596, el primer navío holandés, al mando de Cornelius de Houtman, arribará a aquellos parajes. Todos los horizontes están abiertos. Sigue existiendo, es verdad, la terra incognita en los límites del amplio espacio que (por el conocimiento mismo que se ha ido adquiriendo después) se ha hecho digno del "hombre"...

No debe resultar al lector sorprendente el hecho de que la expansión de los Países Bajos en las Indias Orientales comenzara a fines del mismo siglo en el que Portugal y España, por intermedio del tratado de Zaragosa, habían dirimido sus disputas sobre límites (en favor de Portugal) en aquella región del mundo.$^{38}$ Por una serie de circunstancias ocurridas en Europa, de las que Portugal fue la menos beneficiada, y por la propia dinámica que había llevado al

35 MOLLAT, Michel, Los exploradores del siglo XIII al XVI. Primeras miradas sobre nuevos mundos, Fondo de Cultura Económica, México, 1990, pp. 62-64.

36 ZUMTHOR, Paul, La medida..., Op. Cit., p. 245: "A falta de relación suficientemente explícita, se dudó hasta el siglo XVIII sobre las tierras abordadas por Gonneville en 1505: ¿era Madagascar? ¿Australia? En realidad, se trataba de Brasil.”

37 Ibídem, p. 246.

38 PARRY, John, Europa y la expansión del mundo..., Op. Cit., p. 80: "En 1529, a pesar de la oposición de las Cortes españolas, el tratado de Zaragoza fue firmado en toda regla. Por este tratado, Carlos V cedía a Portugal por 350,000 ducados todos sus derechos a las Molucas, y se fijaba una línea arbitraria de demarcación $17^{\circ}$ al oriente de las islas." 
imperio portugués a controlar el comercio en Oriente, hacia fines del siglo XVI la iniciativa del desenvolvimiento náutico había pasado ya de Portugal a Inglaterra y los Países Bajos. ${ }^{39}$

A la expedición de Cornelius de Houtman en el año 1595 le siguió una serie de viajes financiados por diversas compañías y sindicatos holandeses para comerciar y firmar tratados comerciales con los gobernadores de las distintas islas visitadas. Pero en 1602, los Estados Generales reunirían a las diversas compañías mercantiles del Oriente en la Compañía Holandesa de Indias Orientales, que gozaría del monopolio comercial, entre otras atribuciones económicas y diplomáticas, en el área del Pacífico Sur. ${ }^{40}$

Fue mérito de Jan Pieterszoon Coen la fundación de Batavia (en el extremo norte de la hoy llamada Isla de Jakarta), que pronto devino capital administrativa y naval de las Indias orientales. El control ejercido desde Batavia, a su vez permitió el control de puntos estratégicos en todas las Indias, y con él, la construcción de un sólido imperio colonial dominado por los Países Bajos. ${ }^{41}$ Los resultados del proyecto iniciado por Pieterszoon, sin embargo, se vieron con claridad a mediados del siglo XVII, cuando los Países Bajos finalmente se aseguraron el monopolio del comercio de especias con las Molucas. ${ }^{42}$ Resulta lógico entonces que el itinerario del viaje imaginario narrado por Denis Veiras en 1677 para su protagonista el capitán Siden haya sido la partida desde el puerto de Texel hacia Batavia y una vez en los desconocidos mares australes, el naufragio y posterior llegada a la Tierra Austral.

En relación a este último punto, resulta de interés señalar que más allá del éxito comercial que la incursión holandesa en las Indias Orientales pudo haber significado, en términos geográficos, fueron estas mismas expediciones las que contribuyeron a despejar dudas en torno al conocimiento directo que de aquella zona del globo podía obtenerse; mismo que la incógnita en torno a la existencia o no de una Tierra Austral persistiera. En este sentido, si bien los viajes holandeses no pudieron comprobar la inexistencia de la Terra Australis, cartográficamente debió ser ésta relegada a los $50^{\circ}$ de latitud sur; habiendo demostrado las expediciones que hasta allí sólo había mar:

En el siglo XVII, los buques que hacían el tráfico con la India encontraron miles de millas de mar abierto entre los treinta y los cincuenta grados de latitud sur del Océano Índico. Nada se conocía entonces del verdadero continente antártico. La Terra Australis

39 Ibídem, p. 128.

40 Ibídem, p. 136.

41 En términos de John Parry, el lugar de Batavia fue el de “...mercado central del comercio interasiático, y el depósito general de las mercancías orientales que se exportaban a Europa”, en Ibídem, p. 209.

42 Ibídem, p. 213: "En la segunda mitad del siglo XVII la compañía estableció definitivamente su supremacía naval, comercial y política en las islas, y todos los grandes principados indonesios se derrumbaron." 
de Ptolomeo era por ello relegada a la extremidad sur en algunos mapas y omitida por completo en otros. ${ }^{43}$

En Francia, las epopeyas holandesas fueron conocidas por el público lector a partir de la publicación de las Relations de divers voyages curieux: qui n'ont point esté publiées, et qu'on a traduit ou tiré des originaux des voyageurs françois, espagnols, allemands, portugais, anglois, hollandois, persans, arabes \& autres orientaux del geógrafo y futuro bibliotecario real Melchisédech Thévenot, quien con la publicación de la mencionada serie de relatos inéditos y en gran parte en lengua extranjera, a partir de 1663 verdaderamente suscitó la atención y curiosidad del los ávidos lectores de literatura de viajes sobre el elusivo continente. ${ }^{44}$ Editadas en cinco tomos entre 1663 y 1696, las Rélations de divers voyages curieux... ${ }^{45}$ de Thévenot contenían en sus idiomas originales un sinfín de relatos diversos, ${ }^{46}$ entre ellos textos de suma importancia a los intereses del presente trabajo como las narraciones acerca del descubrimiento de la llamada Tierra Austral y las rutas seguidas por Abel Tasman en su descubrimiento de la Nueva Zelanda ${ }^{47}$ La existencia de compilaciones como la de Thévenot así como también las de Jean Mocquet ${ }^{48}$ o la circulación de los grabados

43 Ibídem, pp. 214-215.

44 CHINARD, Gilbert, L'Amérique et le rêve exotique. La littérature francaise au XVIIeme et au XVIIIeme siecles, Hachette, Paris, 1913, p. 194.

45 El primer tomo será publicado en 1663, el segundo al año siguiente y el tercero en 1666 . Todos ellos bajo el título completo de Relations de divers voyages curieux: qui n'ont point esté publiées, ou qui ont esté traduites d'" Hacluyt, de Purchas et d'autres voyageurs Anglois, Hollandois, Portugais, Allemands, Espagnols et de quelques Persans, Arabes \& autres auteurs orientaux, données au public par les soins de feu M. Melchisedec THEVENOT, Le tout enrichi de figures, de plantes non décrites, d'Animaux innconus à l'Europe et de Cartes Geographiques qui n'ont point encore été publiées, Paris, de l'imprimerie de Jacques Langlois..., 1663. ("Relación de diversos viajes curiosos: que no han sido publicados hasta ahora o que han sido traducidos de Hackluyt, Purchas y de otros viajeros ingleses, holandeses, portugueses, alemanes ...")

46 Figuraba, por ejemplo, la "Relation du P. Jerónimo Lobo de l'Empire des Abyssins, des Sources du Nil, de la Licorne.” ("Relación del P. Jerónimo Lobo sobre el Imperio de Abisinia, los orígenes del Nilo y de Licorne.")

47 En los primeros tomos se encuentran la "Découverte de la Terre Australe, traduite de L'Hollandois, avec une Carte de cette cinquième Partie du Monde" y la "Route d'Abel Tasman autour de la Terre Australe, avec la découverte de la Nouvelle Zelande et de la Terre de Diemens." ("Descubrimiento de la Tierra Austral, traducida del Holandés, con un mapa de esta quinta parte del mundo" y la "Ruta de Abel Tasman alrededor de la Tierra Austral, junto al descubrimiento de la Nueva Zelanda y la Tierra de Diemens.”) Más sobre Tasman y los descubrimientos holandeses en Parry, John, Europa y la expansión del mundo..., Op. Cit., p. 215.

48 Desde principios del siglo XVII las numerosas ediciones del Voyage en Afrique, Asie, Indes 
incluidos por De Bry en su recopilación de Grands y Petits Voyages..., permiten suponer entonces que en Francia a mediados del siglo XVII circulaba un considerable número de obras, comprendidas las cuantiosas relaciones de viaje traducidas del holandés, en las que de manera directa o indirecta se hacía referencia a aquella parte del mundo aún ajena al dominio europeo. ${ }^{49}$

No resulta sorprendente entonces que, tres años después de la edición completa y definitiva de Thévenot, surgiera en Francia el primer relato utópico situado en tierras australes. ${ }^{50}$ Como hemos ya visto, en 1676 Gabriel Foigny publicará en Ginebra La Terre Australe Connue... y al año siguiente, será Denis Veiras quien lo siga con la publicación de L'Histoire des Sévarambes... ${ }^{51}$ A partir de entonces serán muchas las narraciones utópicas que, hasta entrado el siglo XVIII, allí se sitúen.

Como ha sido previamente mencionado, en muchas ocasiones, fueron más los fracasos náuticos que los éxitos los que inspiraron la escritura de textos utópicos. Al respecto, David Fausett se ha encargado de rastraear meticulosamente el impacto ejercido en la escritura de viajes australes imaginarios por la serie de naufragios holandeses en las costas de Australia y sus alrededores en el trascurso del siglo XVII así como también el de las subsiguientes desventuras de sus tripulantes. ${ }^{52}$

En este sentido, tal vez el caso más llamativo sea el de Denis Veiras, quien tomando dos acontecimientos contemporáneos como fueron el hundimiento del Batavia en 1629 y el posterior naufragio del Vergulde Draeck o Dragón Dorado en 1656 en las costas de Australia presentó a los Sévarambes como habitantes de una tierra austral hasta aquél entonces desconocida.

Del hundimiento del Batavia en el arrecife de Houtman Abrolhos en 1629, serán el motín y masacre de la mayor parte de los sobrevivientes, ocurridos tras llegar a tierra firme y conocidos por los contemporáneos a partir del relato escrito por su propio capitán, el ho-

Orientales et Occidentales, obra del encargado del gabinete de curiosidades del Rey Jean Mocquet, no cesaban de demostrar el creciente interés de los lectores por conocer más sobre aquellas tierras australes a través de la literatura. Las mismas aparecieron en París en 1616, y 1617, y en Ruán en 1645 y 1665 además de en varias traducciones, entre ellas la relativamente común edición de Londres de 1696.

49 Y no solamente del holandés. Hacia el final de la cuarta parte Thévenot incluye el relato en español de los "Dos viages del Adelantado Álvaro de Medaña con intento de poblar las Islas de Salomón y descubrir la Parte Austral Incógnita".

50 CHINARD, Gilbert, L’Amérique..., Op. Cit., p. 195.

51 VEIRAS, Denis, (Varaisse), Denis, Histoire des Sévarambes, peuples que habitent une partie du troisiéme continent, communément appellé La Terre Australe. Contentant une Relation du Gourvernement, des Moeurs, de la Réligion, et du Langage de cette Nation, inconnuë jusques à present aux Peuples de l'Europe, Estienne Roger, Amsterdam, 1702.

52 FAUSETT, David, Writing..., Op. Cit. 
landés Francisco Pelsaert, ${ }^{53}$ los que inspiren a Veiras a recrear una catástrofe similar pero de resultados opuestos. Si en 1929 Jeronimus Cornelisz en abierta oposición a Pelsaert y mientras éste había partido hacia Batavia junto a una pequeña flota de sobrevivientes en busca de ayuda había decidido terminar con la vida de hombres, mujeres y niños para optimizar el restante de provisiones, ${ }^{54}$ tras el naufragio ocurrido al comienzo de L'Histoire des Sévarambes, el Capitán Siden se pondrá muy prontamente al frente de los sobrevivientes y organizará de forma expeditiva y severa la vida y comportamiento de los hombres y mujeres bajo su mando. ${ }^{55} \mathrm{Su}$ iniciativa se verá colmada de éxitos, siendo que al cabo de poco tiempo la pequeña comunidad se habrá aprovisionado de víveres, construido un fuerte y reglamentado hábitos tan básicos como aquellos concernientes a la reproducción de la especie.

Publicados por primera vez en 1647, es muy probable que el diario de viaje de Pelsaert junto a un escrito titulado Ongeluckige voyagie van 't schip Batavia o el Desafortunado viaje a bordo del Batavia hayan sido conocidos por Veiras, aunque la posibilidad de que éste último supiera de ello a raíz de la inclusión de fragmentos escritos por Pelsaert en la mencionada Rélation de diverses voyages... de Thévenot tampoco debe ser descartada. Se haya tratado de cualquiera de los dos casos, lo cierto es que esta adaptación sui generis del relato de Pelsaert proporcionó a Veiras de elementos contemporáneos y verídicos a partir de los cuales hacer de su relato un texto igualmente creíble. Si el naufragio del Batavia había llevado a la implantación del autoritarismo más despiadado entre sus sobrevivientes, podía también pensarse en la posibilidad de una organización alternativa y eficiente a la reinante en la metrópolis en tiempos de calma o a la que podía resultar de una situación desesperada.

Más próximo todavía a la publicación de L'Histoire des Sévarambes..., fue el naufragio del Vergulde Draeck, que habiendo partido del puerto de Texel en 1656 y con muchos menos sobrevivientes de los que había tenido el Batavia, jamás fue encontrado en las costas de Australia. ${ }^{56}$ A diferencia del Batavia, el cual Veiras no menciona en la totalidad de la obra, el Vergulde Draeck será la mismísima nave en la que se embarque el ficticio Siden, quien

\section{Ibídem, p. 26.}

54 Hubo un pequeño grupo de hombres que enviado a una isla vecina a buscar provisiones pero pensando Cornelisz que estaban siendo enviados a una muerte segura, encontraron abundante agua y comida. (Ver Ibídem, p. 27.) Es este grupo el que más se asemeja en iniciativa al conducido por Siden tras el naufragio del Vergulde Draeck.

55 Una descripción más detallada de lo sucedido podrá encontrarse en "Falso viaje y verdadera crítica en L'Histoire des Sévarambes (1677) de Denis Veiras", publicado en actas de las VII Jornadas Nacionales de Historia Moderna y Contemporánea. "Diálogos entre el pasado y el presente frente al Bicentenario," Universidad Nacional de Cuyo, Facultad de Filosofía y Letras, Mendoza, octubre de 2010.

56 Para obtener una explicación más detallada del naufragio y de las numerosas expediciones enviadas para rescatar a sus tripulantes y cargo ver FAUSETT, David, Writing..., Op. Cit., Capítulo VII: Shipwreck and Marooning in the Southland, pp. 98-112. 
en busca de riqueza y aventuras partirá rumbo a Batavia junto al resto de la tripulación. Así como con Foigny un año antes, la necesidad del género utópico de crear un marco verosímil en el cual insertar a las sociedades imaginadas hará que Veiras tome de los recursos más próximos la información necesaria para generar en el lector la ambigua sensación de estar leyendo un relato no del todo ficticio. Además de incluir en L'Histoire des Sévarambes..., la pérdida del Dragón Dorado, el autor, que acompañando en misión diplomática a los Países Bajos al Duque de Buckingham en 1672 había probablemente escuchado sobre el naufragio, tampoco dudará en darle muerte a Siden en el conflicto naval que involucró a Inglaterra y Holanda ese mismo año. En el mismo sentido, que proveyera los verdaderos nombres del gobernador de Batavia y de un agente de la Compañía Holandesa de Indias Orientales, contribuyó también en agregar una fuerte cuota de realidad al relato utópico.

En relación a la temática del viaje ultramarino propiamente dicha, no resulta extraño suponer que la suerte de Siden podría haber sido también la desventura de Pelsaert. Asimismo, la isla desierta a la que arriba la tripulación del Batavia tras naufragar podría no necesariamente haberlo estado. El hecho de que los mismos lectores y críticos literarios muchas veces hayan confundido el carácter de estas piezas literarias pareciera demostrar al igual que lo antedicho, que en materia de tierras australes, hasta entrado el siglo XVIII, la especulación y la experiencia no habían logrado aún separarse en dos campos claramente delimitados. ${ }^{57}$

En materia de viajes exploratorios, hemos visto entonces como desde el relato de Pigafetta sobre el primer viaje alrededor del mundo ${ }^{58}$ hasta los relatos holandeses contemporáneos a la escritura de utopías australes, la Tierra Austral en tanto representación de un espacio desconocido, alimentado por las imágenes fantásticas producidas en consonancia con los nuevos descubrimientos, o por las desventuradas crónicas producto de los naufragios en el Pacífico Sur, no solamente fue parte integral de los objetivos con los que se planificaron las expediciones ultramarinas de exploración sino que también devino un espacio del que la literatura utópica se apropió en tanto no-lugar.

Respecto del primer punto, aunque más no sea brevemente, a continuación veremos como en el caso francés, terminada la fase de exploración, ${ }^{59}$ la posibilidad aún abierta de dar con tales tierras motivaría las expediciones ultramarinas organizadas a lo largo del

57 Ibídem, p. 34: “... in utopias a real context of travel and commerce - an imaginary voyage - was either implicit or explicit and lent an air of anxiety and ambivalence." (Traducción de la autora: "... en las utopías un contexto de viaje y comercio reales -un viaje imaginario- estaba o implícito o explícito y proveía un halo de ansiedad y ambivalencia."

58 En él aparecía ya reformulado un compendio de figuras simbólicas atribuidas tan tempranamente a la Tierra Austral como desde los relatos de Marco Polo o presentes en los cuentos orientales llegados a Europa para esa misma época.

59 Mollat divide el proceso de expansión ultramarina en dos etapas. La primera, articulada en torno a los viajes de exploración, y la segunda, basada sobre todo en la conquista. 
siglo XVII, pero ante todo aquellas iniciadas a mediados del siglo XVIII, en la esperanza de proporcionar territorios nunca antes reclamados ni descubiertos a un rezagado imperio en términos de expansión colonial. Recordemos que:

a pesar de algunos intentos abortados en tiempos de Francisco I, Francia no emprend[ió] la gran aventura espacial hasta principios del siglo XVII, y jamás con tanta determinación como los burgueses de Holanda, que también salieron con mucho retraso. ${ }^{60}$

\section{La construcción de un espacio como móvil de la conquista}

En la Francia de mediados del siglo XVIII, tanto el acto de incentivar el descubrimiento de tierras australes como la ejecución misma del proyecto colonial francés, estuvieron profundamente marcados por dos figuras paradigmáticas del deseo francés por ubicarse dentro del concierto de las grandes potencias europeas con posesiones coloniales: fueron ellas las de Charles De Brosses y Louis Antoine de Bougainville.

El caso de De Brosses resulta de particular importancia al poner en evidencia que el interés (tanto político como comercial) de la corona francesa por las tierras australes no decrecerá en el siglo XVIII. En efecto, en 1756 aparecerá, con la aprobación y el privilegio del rey, y a instancias de Buffon, la Histoire des navigations aux Terres Australes..., en dos volúmenes in quarto ${ }^{61}$ que será a su vez publicada junto a una detallada serie de mapas cartográficos sobre cada una de las regiones meridionales abordadas, incluyendo las de Australasia y Polinesia (nombres atribuidos a estas regiones por el mismo De Brosses).

El objetivo resultaba por demás claro: alentar al descubrimiento y establecimiento de colonias francesas en las tierras australes por descubrir. En este sentido, en el Prefacio, De Brosses explicaba el sinnúmero de beneficios que tales acciones podían acarrear: "Il fit en effet ce mémoire, dans lequel il s'attacha principalement à montrer en général qu'une telle découverte apporteroit réellement beaucoup de gloire à la nation, \& de grandes utilités à son commerce." ${ }^{\prime 2}$ Organizada en cinco partes, cada una comprendía la serie de viajes y descubrimientos que, desde la primera circunnavegación realizada por Magallanes, habían aportado información acerca de las tierras australes. ${ }^{63}$ De los relatos de viaje de circunnaveg-

60 ZUMTHOR, Paul, La medida..., Op. Cit., p. 244.

61 La obra fue publicada bajo el título completo de DE BROSSES, Charles, Histoire des navigations aux Terres Australes contenant ce que l'on sait des moeurs et des productions des contrées découvertes jusqu'a ce jour; et où il est traité de l'utilité d'y faire de plus amples découvertes, et des moyens d'y former un établissement, à Paris, Chez Durand, 1756.

62 DE BROSSES, Charles, Histoire des navigations aus Terres Australes..., Op. Cit. p. lj. ("Hizo en efecto esta memoria, en la cual se avocó principalmente a mostrar en general que tal descubrimiento traería realmente mucha gloria a la nación y grandes beneficios a su comercio.")

63 La quinta parte, resultaba para De Brosses la más interesante. En ella: “On y discute les avantages et 
ación posteriores, de hecho, De Brosses dice haber incluido solamente aquellas partes que comprendían a la Tierra Austral: “... on supprime ici une infinité de choses intermédiaires, en un mot tout ce qui n'est pas récit des Terres Australes." ${ }^{64}$ L'Histoire des navigations... encarnaba así el deseo de la Corona por alentar la conquista y colonización. Sus efectos se verían pocos años después con el primer y segundo viaje oficiales a los mares del sur a cargo de Louis Antoine de Bougainville.

En efecto, el autor del Voyage autour du monde..., fue capitán del primer navío francés en realizar un viaje alrededor del mundo. La obra, publicada en 1771 a raíz del viaje y vuelta a editar, corregida y aumentada en 1772, se presentó al público como la versión adaptada del Journal que Bougainville había redactado en el transcurso del viaje. ${ }^{65}$

Como agente del Estado o funcionario real,${ }^{66}$ en 1766, Bougainville, aunque con motivos diplomáticos que justificaban el viaje al menos en sus orígenes, ${ }^{67}$ emprendería el primer viaje de circunnavegación francés con la función de hallar nuevos territorios en la zona del Pacífico Sur que (desconocidos por las otras potencias europeas) pudiesen convertirse en colonias de dominio francés. Al parecer, dicha misión se había originalmente acordado tras la firma del Tratado de París en 1763 (corolario de la derrota militar de Francia en Canadá y testimonio de sus pérdidas coloniales) cuando Bougainville, motivado por su lectura de De Brosses, había sugerido a la Corona francesa financiar "un proyecto de dudosa legalidad: tomar posesión de las tierras australes y de las islas que se encontrasen en dicha ruta." ${ }^{68} \mathrm{En}$ este sentido y tal como había intentado hacer en el viaje anterior con las Islas Malvinas,

les désavantages d'un établissement pour chaque lieu différent; au cas que le gouvernement françois prit un jour la pensée d'y faire un entrepôt de commerce, ou d'y fonder une colonie... Ce cinquième livre, fondé sur l'autorité des textes originaux qui le précèdent a paru le plus agéable à lire" (Ibídem, p. X) ("Se discuten las ventajas y desventajas de un establecimiento en cada sitio diferente, en el caso de que el gobierno francés decida un día crear un establecimiento y fundar una colonia. Ese quinto libro, basado en la autoridad de los textos originales que lo preceden ha parecido el más agradable para leer.")

64 Ibídem, p. Viij. (“... se suprimen aquí una infinidad de cosas intermedias, en una palabra, todo aquello que no versa sobre las Tierras Australes.")

65 Siendo el mismo Bougainville quien efectuaba los sucesivos procesos de selección y autocensura en función de jerarquizar o acomodar según sus propios intereses el relato de viaje.

66 Dice Bougainville en su dedicatoria al Rey: "Soy, con el más profundo respeto de Vuestra Majestad, Señor, el muy humilde y muy sumiso servidor y súbdito."

67 Partía en misión oficial con el objetivo diplomático de devolver la posesión de las Islas Malvinas a la Corona española.

68 BOUGAINVILLE, Louis Antoine, Viaje alrededor del mundo a bordo de la fragata real la Boudeuse y la urca Étoile, en 1767, 1768 y 1769, Eudeba, Buenos Aires, 2005, p. 26. 
al llegar a Tahití, no dudará en enterrar en la misma un acta de posesión estableciendo el dominio francés sobre la isla. ${ }^{69}$

Tampoco debería olvidarse que en materia de viajes imaginarios, la expedición emprendida por Bougainville también tendrá su corolario utópico en el Supplément au voyage de Bougainville de Denis Diderot (1772). A partir de la descripción de una sociedad cuasi utópica en la isla de Tahití, a la que el mismo Bougainville había ya atribuido características paradisíacas, Diderot procederá a la mordaz crítica de la moral, religión y costumbres de la Francia de Antiguo Régimen. ${ }^{70}$ Con el objetivo de evaluar la sociedad propia, la isla de Tahití funcionará entonces como espejo ejemplarizador y será, esta vez en un sentido literario, aquél orbis alterius que conceptual y geográficamente desde la antigüedad clásica había sido concebido para significar aquello que la tierra conocida no era.

Más allá de esto último, en relación al proyecto colonial ideado por la Corona, puede verse entonces como en el caso francés, la esperanza de encontrar aquél continente austral que hasta el momento parecía sólo existir en mapas, operó entonces como un fuerte aliciente y a la vez justificó los intentos de un imperio rezagado en la carrera ultramarina y, muy recientemente debilitado tras la pérdida de Canadá, por ocupar espacios hasta el momento bajo exclusivo control de las potencias rivales. En este sentido, más allá de la existencia real o no de una Tierra Austral, fue la construcción de la misma en tanto espacio "deseable" en el horizonte de la expansión ultramarina la que justificó los intentos de colonización posteriores a la primera oleada de descubrimiento y conquista.

\section{Desmitificación y cambio de paradigma. Algunas reflexiones finales}

Como bien ha señalado Marie-Noëlle Bourguet, fueron las mismas expediciones impulsadas por los escritos de De Brosses, Maupertuis y Buffon (iniciadas tras la paz relativa garantizada por el Tratado de París), así como también los viajes ingleses al extremo sur del mundo, los que finalmente dieron por tierra con el mito de la Terra Australis. ${ }^{71}$ De todos estos exploradores, fue Cook quien hacia 1771 en sus navegaciones por el Pacífico Sur, terminó por comprobar la inexistencia de aquella gran masa continental tan presente en la mente de los exploradores de la modernidad temprana europea.

En 1768, bajo las órdenes de la Royal Society, partiría Cook con la misión de realizar

69 Ibídem, p. 197.

70 Ver MARTÍNEZ, Carolina, "Utopía, alteridad y felicidad en el proyecto ilustrado. El Supplément au voyage de Bougainville de Denis Diderot como expresión misma de las máximas de la Ilustración," en GANDINI, María Juliana, LÓPEZ PALMERO, Malena, MARTÍNEZ, Carolina, PAREDES, Rogelio C., Dominio y reflexión. Viajes reales y viajes imaginarios en la Europa moderna temprana (siglos XV a XVIII), Editorial de la Facultad de Filosofía y Letras, Buenos Aires, 2011, pp. 215-245.

71 BOURGUET, Marie Noëlle, "Voyages et voyageurs", en Dictionnaire Européen des Lumières, P.U.F., Paris, (sous la direction de Michel Delon), 1997. 
investigaciones geográficas en el Pacífico meridional. El hecho de que el capitán inglés comprobara la inexistencia de la Tierra Austral, modificaría radicalmente la representación del mundo que hasta entonces había provisto la cartografía moderna:

En el segundo Viaje, con el Resolution y el Adventure, tocó el Cabo, rebasó el Círculo Polar Antártico, y volviendo a Nueva Zelandia, desvaneció el mito de la existencia de un continente austral. ... Cruzó el Pacífico Central hacia las Nuevas Hébridas ...., y tras cruzar y recruzar el vasto Pacífico en la totalidad de su extensión desde el sur de Australia ... desvaneció igualmente la hipotética existencia de la Terra australis.... ${ }^{72}$

Resultaba ya evidente que desde la experiencia y la técnica desarrolladas en el siglo XVIII, la tierra austral incógnita, en tanto espacio geográfico en el imaginario europeo, no se correspondía ya con una representación "real" del mundo.

Entre los siglos XVI y XVIII, sin embargo, la tierra austral incógnita tanto en términos geográficos así como tópico en la literatura de viajes europea de la temprana modernidad, había jugado un papel de singular importancia al cumplir con la doble función de justificar la expansión ultramarina y a su vez convertirse en depositaria de las múltiples sociedades imaginarias que en esta época se concibieron. En el caso de Francia particularmente, el impacto simbólico ejercido por la terra australis incognita en tanto definición, apropiación y construcción de un espacio en la literatura utópica del siglo XVII y hasta mediados del siglo XVIII, fue crucial al proveer al escritor de utopías de un punto geográfico verosímil desde donde instalar un discurso utópico que fuese a su vez centro de la alteridad más absoluta.

Recibido: 03/10/2011

Aceptado: 20/11/2011

72 COOK, James, Relación de su Primer Viaje alrededor del mundo durante los años 1768, 1769, 1770 y 1771, Traducido del inglés por M. Ortega y Gasset, Calpe, Madrid, 1922, p. XI. 